\title{
Suicide trends in the South-East Thames Region
}

\author{
Dinesh Bhugra, Senior Registrar, Bethlem Royal Hospital, Monks Orchard Road, \\ Beckenham, Kent BR3 3BX (correspondence); and JOHN WATSON, Eastbourne \\ Health Authority, 9 Upperton Road, Eastbourne, East Sussex
}

Suicide rates in the Eastbourne Health District have risen dramatically over the last ten years. The present study looks at some of the factors which may influence these rates and compares these with other health districts in the South East Thames Region. Suggestions for further research are made.

Suicide rates vary from country to country and also within the same country. Ross \& Kreitman (1975) showed that the rates of suicide were lower in Scotland in comparison with England and Wales, in spite of similar criteria employed for assessment of suicide. Atkinson et al (1975) emphasised that the suicide figures are important to evaluate the capacity of various systems to procure happiness and security for their members. Cultural attitudes to suicide are said to determine the definition of suicide (Douglas, 1967). Sainsbury (1983) recommended using the official figures because the statutory process of investigating violent deaths goes a long way towards providing an operational definition of a "case" and also identifying such "cases". Psychological causes Beratis (1986) drastically changed living conditions (Jacobsson \& Renberg, 1986), alcoholism (Kreitman, 1972), mental illness (Barraclough et al, 1974), loss of status (Yap, 1963) etc. are some of the factors related to suicide.

\section{The study}

The present study looks at the data available for suicides in all 15 health districts of the South-East Thames Regional Health Authority (SETRHA). The data were obtained from SETRHA census department. The study compares the rates in various districts but focuses closely on Eastbourne Health District. Three year rolling data have been used to reduce the wide variations produced by small statistics. Standard Mortality Rate (SMR) has been used in this study to look at the mortality rates.

\section{Findings}

The SMRs for suicide in SETRHA in 1983-85 were highest in West Lambeth [132] with Eastbourne [122] slightly behind Camberwell. The lowest rates were in Dartford and Gravesham [61]. Looking at the sex distribution of suicides in the region, it was apparent that among the females the highest SMR was in Brighton whereas for males the highest SMR was in Camberwell. Bexley and Medway had the lowest rates among females and males respectively.

The actual numbers of deaths in any year is small. In order to reduce the effect of these small statistics they have been analysed over number of years by aggregating them into three year groups. This showed that the Eastbourne rates were lower than average until 1980-81. They have exceeded the average in each of the subsequent three yearly groups.

This rising trend has been evident for both sexes but is most marked for males. Among the females in Eastbourne there are two peaks at the age groups of 45-54 years and at 75-84, the former being a smaller peak of the two. In the region there is a steady climb with a relatively smaller peak at the age group of 75-84 years. Among the males, however, the peak appears later at $85+$. The regional figures for the males are evenly spread through all ages though there is a trough at $45-54$ years in contrast to female group.

There were 28 [male 20: female 8] deaths certified as due to suicide by residents of Eastbourne district in 1985. This gives a crude death rate of 0.12 per 1,000 population. When adjusted for the age and sex structure this exceeds the regional rate in the proportion of $122: 100$. This is in a district where the overall death rates are lower than those in England and Wales and those for the region [90: 96: 100].

\section{Discussion}

The SMRs for suicide among both sexes are higher in the Eastbourne district compared to other districts in the Region. Looking specifically at figures for 19831985 , it appears that SMR for all causes of death was lower in Eastbourne Health District compared to national figures, whereas SMR for suicide [122] was much higher than the average for the Region [100], although only marginally lower than those in West Lambeth and Camberwell districts. The high rates in these areas could be explained by its being an inner city area where psychiatric morbidity and social deprivation are likely to be high; but the high rates in Eastbourne are difficult to explain. The three 
London Health Districts, on the other hand, have always had higher suicide rates.

Looking at the age distribution of suicide rates in Eastbourne in 1985, it becomes apparent that even though SMR due to all causes of death is lower than the Region and England and Wales [90: 96: 100 respectively], the difference changes dramatically when looking at the suicide rates. The suicide rates which were $40 \%$ below the national rates a decade ago are now $40 \%$ above. Admittedly there has been a steady slight increase in suicide rates nationally, which is possibly explained by increase in male suicide rates. In Eastbourne Health District this increase, certainly for 1985 , is much more obvious among the elderly over 85 . Even though increase in female rates may have contributed to increase in Eastbourne, the peaks are at younger age groups. It appears then that people are living longer in the district and yet are proportionately more dissatisfied with their lot. This has obvious implications for service and care givers. It would be useful to compare the differences between other [coastal] districts with higher population of the elderly and Eastbourne. Preliminary analysis of the data from Eastbourne shows that elderly widowed men are more at risk and over half the cases had some form of identifiable psychiatric illness [depression outnumbering all the rest] even though help was sought by only a few (Bhugra, in preparation).

The incidence of 'suicidal gestures' needs to be monitored across various parts of the Region as well as England and Wales along with suicide rates. Repeated suicidal intent is said to accompany an increasing suicidal intent (Pierce, 1984). The availability of and access to crisis intervention services is of paramount importance in any attempts to reduce the suicide rates, which can be done (Hoffman \& Modestin, 1987). These will have obvious implications for service provisions.

It must be remembered that this information relates only to those deaths registered as due to suicide. Open verdicts and accidental deaths likely to be suicides are not represented in this data. There may be an underestimate of the true incidence. More co-ordinated and concerted studies are needed to compare the suicide rates and factors like unemployment, mental illness, availability and usage of services need to be looked at.

With an increase in community based services and sectorisation of services with the financial implications thereof, the differences across communities and health districts need to be looked at. The aims of reducing suicide rates need a high level of cooperation between health, social, education and voluntary agencies. The earlier identification and help of the bereaved and the lonely by care agencies and families need to be encouraged. Discharged psychiatric patients in the community may require greater support than is available. Telephone helplines and crisis contacts may need to be provided for aftercare. If the trends of high suicide rates among the elderly persist the life-skills training, use of leisure and recreational opportunities as part of preretirement training would need to be developed. The areas highlighted by the suicide rate represent major health care needs in the society and present a major challenge to psychiatrists and other agencies and concerted efforts need to be made to reduce the trauma and the misery.

Full details of the study are available on request from the authors.

\section{References}

Atkinson, M., Kessel, N. \& Dalgand, J. (1975) The comparability of suicide rates. British Journal of Psychiatry, 127, 247-256.

Barraclough, B., BunCh, J., Nelson, B. \& SAInsBury, P. (1974) A hundred cases of suicide: clinical aspects. British Journal of Psychiatry, 125, 355-373.

BERATIS, S. (1986) Suicide in south western Greece 1979 1984. Acta Psychiatrica Scandinavica, 74, 433-439.

BHUGRA, D. (1987) Clinical profile of suicides in Eastbourne (in preparation).

Douglas, G. D. (1967) The Social Meanings of Suicide. Princeton University Press.

HoffMAN, H. \& MODESTIN, J. (1987) Suicide in discharged psychiatric inpatients. Social Psychiatry, 22, 93-98.

JACOBSSON, L. \& RENBERG, E. (1986) Epidemiology of suicide in a Swedish county (Vasterbotten) 1961-1980. Acta Psychiatrica Scandinavica. 74, 459-468.

Kreitman, N. (1972) Suicide in Scotland in comparison with England and Wales. British Journal of Psychiatry, 120, 83-87.

PIERCE, D. (1984) Suicidal intent and repeated self-harm. Psychological Medicine, 14, 655-659.

Ross, O. \& KREITMAN, N. (1975) A further investigation of differences in the suicide rates of England and Wales and of Scotland. British Journal of Psychiatry, 127, 575-582.

SAINSBURY, $P$. Validity and reliability of trends in suicide statistics. World Health Statistics Quarterly, 35, 339-348.

YAP, P. (1963) Ageing and mental health in Hong Kong. In Process of Ageing, vol. II (eds. R. William, C. Tibbits \& W. Donahue). New York: Atherton Press. 